\title{
Recycling Polymer-Rich Waste Printed Circuit Boards at High Temperatures: Recovery of Value-Added Carbon Resources
}

\author{
V. Sahajwalla $\cdot$ R. Cayumil $\cdot$ R. Khanna \\ M. Ikram-Ul-Haq • R. Rajarao • \\ P. S. Mukherjee $\cdot$ A. Hill
}

Published online: 8 January 2015

(C) The Minerals, Metals \& Materials Society (TMS) 2015

\begin{abstract}
High-temperature transformation studies were carried out on polymer-rich waste printed circuit boards (PCBs) in the temperature range of $750-1,350{ }^{\circ} \mathrm{C}$ in argon atmosphere. Copper-rich metallic fractions started to separate out as foils/droplets at temperatures above $950{ }^{\circ} \mathrm{C}$ producing significant quantities of carbonaceous residue. In-depth characterisation of the residue was carried out using X-ray diffraction, Raman spectroscopy, SEM/EDS, surface area analysis, and LECO measurements. The recovery of carbons from waste PCBs reached up to $25 \%$ of total weight. These carbons generally had a disordered structure with 3-4 layers stacking along the c-axis. The presence of metals in the carbonaceous residue became negligibly small at $1,350{ }^{\circ} \mathrm{C}$, significantly enhancing the quality of the carbonaceous product (carbon content: 52-74 wt \%). This study has shown that potentially vast reserves of carbon could be recovered from e-waste through appropriate recycling, while minimising the impact of waste on the environment.
\end{abstract}

V. Sahajwalla $\cdot$ R. Cayumil $\cdot$ R. Khanna $(\bowtie)$.

M. Ikram-Ul-Haq · R. Rajarao

Centre for Sustainable Materials Research and Technology (SMaRT), School of Materials Science and Engineering, The University of New South Wales UNSW Australia, Sydney, NSW 2052, Australia

e-mail: ritakhanna@unsw.edu.au

\section{P. S. Mukherjee}

Advanced Materials Technology Department, CSIR-Institute of Minerals and Materials Technology, Bhubaneswar 751013, India

A. Hill

CSIRO Process Science \& Engineering, Clayton, Melbourne, VIC 3168, Australia
Keywords Recycling - E-waste - Disordered carbons · PCBs - Thermal transformations

\section{Introduction}

Electronic waste (e-waste) is one of the fastest growing solid waste streams around the world today [1]. Rapid uptake of information technology with the advent of new designs and technology at regular intervals and intense marketing in the electronics sector is causing the early obsolescence of many electronic items. With high consumer demand in affluent countries, and even amongst developing economies, the manufacturing and sales of equipment in the electronic industry is now $\sim \$ 1$ trillion annually, yielding 30-50 million tonnes of obsolete equipment worldwide each year [2, 3]. The international association of electronics recyclers projects that $\sim 3$ billion computer products units including CPUs, monitors, notebooks, keyboards, printers, copiers, faxes, etc. will be scrapped by 2015 [4]. In Australia, an estimated 37 million computers will be in landfills or on their way; another 4 million computers are expected to be sold every year and less than $1.5 \%$ will be recycled [5]. A similar scenario exists for TVs, mobile phones, fluorescent tubes and other electronics. With an overall recycling rate of only 10-18\% worldwide, most of the discarded electronic equipment are stored in warehouses, off-shored to developing economies, trashed in landfills or incinerated $[6,7$, 8].

E-waste is known to be a complex mixture of plastics, metals, ceramics and other trace impurities; it can contain up to 1,000 different substances [9]. PCBs typically contain $40 \mathrm{wt} \%$ metals, $30 \mathrm{wt} \%$ organics and $30 \mathrm{wt} \%$ ceramics. However, there is a great variance in the composition of 
PCB (PCB: the central component in electrical and electronic devices), wastes coming from different appliances, from different manufacturers and of different ages. After removing batteries and capacitors, PCBs from computers/ TVs can contain up to $70 \mathrm{wt} \%$ organics, whereas PCBs from mobile phones contain $\sim 20 \mathrm{wt} \%$ organics [10]. There is a potential material resource of over 40 million tonnes a year in e-waste which could be used again and again if appropriate recycling practices are put in place.

A number of approaches such as metallurgical (hydro, bio and pyro) techniques, chemical techniques and lowtemperature pyrolysis are being used to recover materials from the e-waste $[11,12]$. Due to economic reasons, recycling efforts are generally focused on the recovery of copper and other/precious metals from the waste electronics as the metallic concentrations in waste printed circuit boards (PCBs) can be several times higher than their respective ores [13]. The nonmetallic fraction containing large amounts of carbon is either burnt to provide energy during recycling or is trashed as a waste by-product. Our focus in this article is to investigate the formation and characterisation of residual carbons during high-temperature transformations of waste PCBs.

A number of pyrolysis investigations on waste PCBs/ewaste have been reported in the literature. In the Haloclean process, the e-waste is first heated at $350{ }^{\circ} \mathrm{C}$ and then at $450{ }^{\circ} \mathrm{C}$ under nitrogen in a horizontal rotary kiln; this process generates a gas/oil fraction that can be concentrated as oil and a solid residue from which metals can be recovered after further treatment [14]. Zhou et al. [15] conducted a three-step pyrolysis process: in the first stage, a PCB was pyrolysed at $600{ }^{\circ} \mathrm{C}$ under vacuum; the second step involved the vacuum centrifugal separation of the solder. In the last step, the solder was re-melted, and the products generated were $\sim 72 \mathrm{wt} \%$ of solid residue composed of metals, glass fibres and other inorganic materials; $22 \mathrm{wt} \%$ of oil fraction containing tin and lead; and $6.35 \mathrm{wt} \%$ gaseous products [15]. Another investigation involved the heating of a mixture of PCBs and molten salts, $\mathrm{KOH}$ and $\mathrm{NaOH}$ at $300{ }^{\circ} \mathrm{C}$ under argon flow. Two solid products were obtained: a metallic fraction composed of wires and foils and a calcium carbonate/calcium silicate powder [16]. de Marco et al. investigated four different materials: polyethylene (PE) wires containing $\mathrm{Al}$ and $\mathrm{Cu}$ from e-waste, table phones, mobile phones and PCBs; these were heat treated at $500{ }^{\circ} \mathrm{C}$ under nitrogen atmosphere. The solid products generated were inorganic materials consisting mainly of metals and a black powder/char. The amount of char recovered was low for PE materials and PCBs, and high for both types of phones. Pyrolysis oil consisting of organic compounds was also generated; gaseous products were mainly hydrocarbons along with large amounts of $\mathrm{CO}$ and $\mathrm{CO}_{2}$ [17].
In a recent study by our group, the pyrolysis of waste PCBs at $1,150{ }^{\circ} \mathrm{C}$ in argon atmosphere led to a clear separation of various metals from a carbonaceous and ceramic residue; this was attributed to the poor affinity of carbon with copper/copper-based alloys [18]. In the present investigation, studies were carried out on thermal transformations of waste PCBs in the temperature range from 750 to $1,350{ }^{\circ} \mathrm{C}$. In this article, we report the generation of significant quantities of carbonaceous residues following the separation of most of the metallic phase as droplets or foils. Along with an in-depth investigation on polymer degradation and gaseous release, a range of analytical tools were used to characterise these carbonaceous residues. This investigation was carried out on polymer-rich single-sided PCBs that dominate the electronics market in sheer volumes and are a dominant fraction of waste PCBs from obsolete, old-generation electronic devices.

\section{Materials and Methods}

A schematic diagram of the experimental set up is shown in Fig. 1a. Waste polymer-rich PCB fragments were manually cut to a size of $\sim 1 \mathrm{~cm}^{2}$ from a range of computer motherboards. Several pieces together weighing $\sim 2 \mathrm{~g}$ were placed in an alumina crucible and placed on an alumina holder. Waste PCBs are composed of a heterogeneous and a complex mixture of elements. Average concentration of major metals in the waste PCBs under investigation were copper $(\sim 13 \mathrm{wt} \%)$, tin $(4.8 \mathrm{wt} \%)$ and lead $(3.1 \mathrm{wt} \%)$. Refractory components included silicon oxide, aluminium oxide, alkaline and alkaline-earth oxides; additional phases such as barium titanate, potassium, magnesium and aluminium silicates were also present in some boards.

This assembly was pushed into the cold zone $\left(200-300^{\circ} \mathrm{C}\right)$ of a high-temperature horizontal tube furnace with the help of a graphite rod. The reaction assembly was held there for 10 min to avoid thermal shock, and then pushed into the hot zone of the furnace, maintained in the temperature range $750-1,350{ }^{\circ} \mathrm{C}$. A few studies were also carried out at $1,550{ }^{\circ} \mathrm{C}$ as well. High-purity argon gas was passed through the furnace tube at a rate of $1 \mathrm{~L} / \mathrm{min}$ during the heat treatment. The gas outlet was connected to an Infrared (IR) gas analyser for a continuous monitoring of $\mathrm{CO}, \mathrm{CO}_{2}$ and $\mathrm{CH}_{4}$ gases produced during the heat treatment. Previous studies from our group had carried out heat treatment of PCBs as a function of time $(1,2,5,10,15,20$, and $30 \mathrm{~min}$ ); the thermal degradation of PCBs was found to be nearly complete within $15 \mathrm{~min}$ at these temperatures [18]. In this study, the exposure of waste PCBs to high temperature was therefore carried out for $20 \mathrm{~min}$; specimens were pulled back into the cold zone and kept there for $30 \mathrm{~min}$ to avoid thermal cracking and the re-oxidation of residual products. 


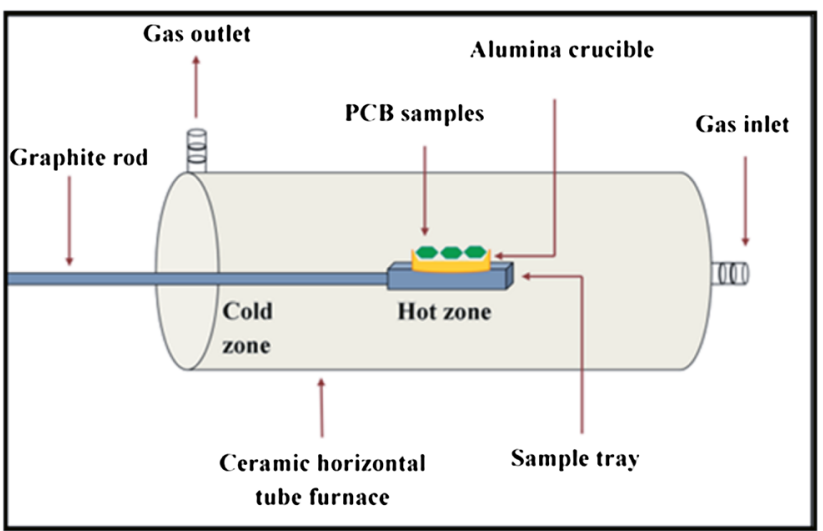

(a)

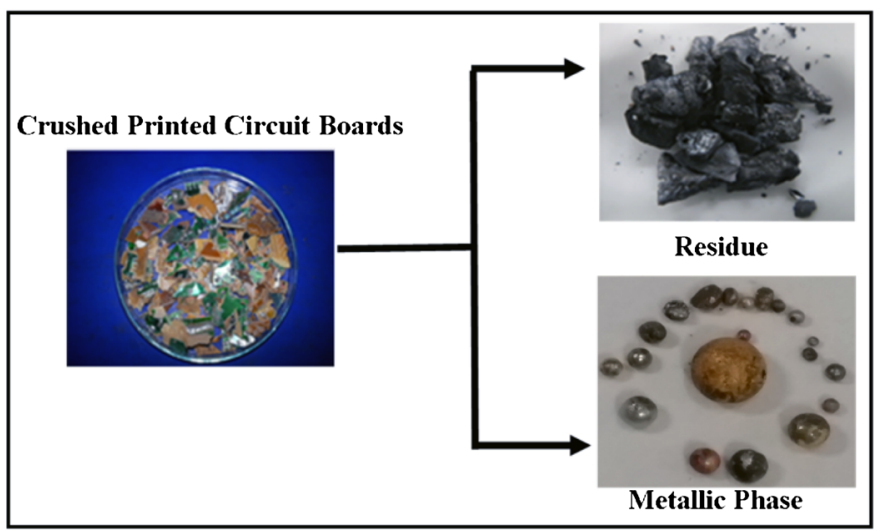

(b)

Fig. 1 a A schematic representation of the experimental arrangement, $\mathbf{b}$ the carbonaceous residue and the metallic phase produced after heat treatment of waste PCBs at $1,150{ }^{\circ} \mathrm{C}$

Experiments were repeated several times at each temperature to enhance the reproducibility of results. Figure $1 \mathrm{~b}$ shows samples before and after the heat treatment. The reaction products after the heat treatment could be separated into metallic droplets/foils, and a dark carbonaceous phase/slag. Relative proportions of various phases in the residue showed sample-to-sample variation and could not be ascertained accurately. Even though a significant proportion of metals were separated, a small quantity of residual metals still remained within the carbonaceous residue as indicated by ICP analysis. It was also difficult to separate out slag phases from carbons; however, a rough estimate of relative proportion of carbon in the residue was obtained from LECO analysis. These results have been provided in later sections. The weights of the samples were measured before and after the heat treatment; the carbon content of the carbonaceous residue was measured using LECO CN TruSpec Analyser.

The low-temperature thermal degradation of $\mathrm{PCB}$ polymers was also investigated using TGA/FTIR (Thermogravimetric-analyser model Perkin Elmer Pyris 1) for temperatures up to $1,350{ }^{\circ} \mathrm{C}$ to study volatile release during continuous heating at the rate of $20{ }^{\circ} \mathrm{C} / \mathrm{min}$. The carbonaceous phase was analysed using $\mathrm{x}$-ray diffraction, Raman spectroscopy, Scanning Electron Microscopy (SEM/EDS) model Hitachi S3400X, and Inductively Coupled Plasma Optical Emission Spectrometers model, Perkin Elmer Optima 7300DV (ICP-OES) techniques. Our previous studies on carbonaceous residues from hightemperature pyrolysis of waste PCBs had shown the generation of carbon microfibres and foams [19]. BET surface area analysis was carried out by using Micromeritics Tristar 3000 to determine the area of pores generated by escaping gases during polymer degradation. Samples were dried for $3 \mathrm{~h}$ at $150{ }^{\circ} \mathrm{C}$ under vacuum.
Surface area and pore distribution were studied through the nitrogen physio-sorption technique. Twenty-point adsorption and 20-point desorption isotherms were generated and were used to determine specific surface area using the BET model. The pore distribution was determined through BJH model [20].

\section{Results}

\section{Weight Loss and Carbon Content}

The weight loss in waste PCBs heat treated for 20 min was measured at various temperatures ranging from 750 to $1,350{ }^{\circ} \mathrm{C}$; the average weight loss from sets of at least six measurements is shown in Fig. 2a. Data scatter in the results has also been indicated in the figure. This weight loss is attributed mainly to polymer degradation, volatiles and subsequent gas release. Thermogravimetric analysis (TGA) was also carried out to determine polymer degradation during continuous heating to $1,350{ }^{\circ} \mathrm{C}$ at a heating rate of $20{ }^{\circ} \mathrm{C} / \mathrm{min}$; the TGA and DTG results have been plotted in Fig. 2b. The pyrolysis of waste PCBs showed two stages of weight loss at 320 and $460{ }^{\circ} \mathrm{C}$. The thermal decomposition of waste PCBs began at $300{ }^{\circ} \mathrm{C}$ and a significant loss of mass occurred between 300 and $500{ }^{\circ} \mathrm{C}$. The maximum weight loss was found to occur $\sim 330{ }^{\circ} \mathrm{C}$; the mass loss slowed down significantly at higher temperatures and was less than $8 \mathrm{wt} \%$ between 500 and $1,350{ }^{\circ} \mathrm{C}$. This weight loss at higher temperatures can be attributed to the generation of $\mathrm{CO} / \mathrm{CO}_{2}$ gases during reduction reactions and the loss of lead in the vapour phase. Previous studies from our group on polymer degradation were carried out on pure polymers and coke/polymers blends [21]; present studies on waste PCBs, which are a 


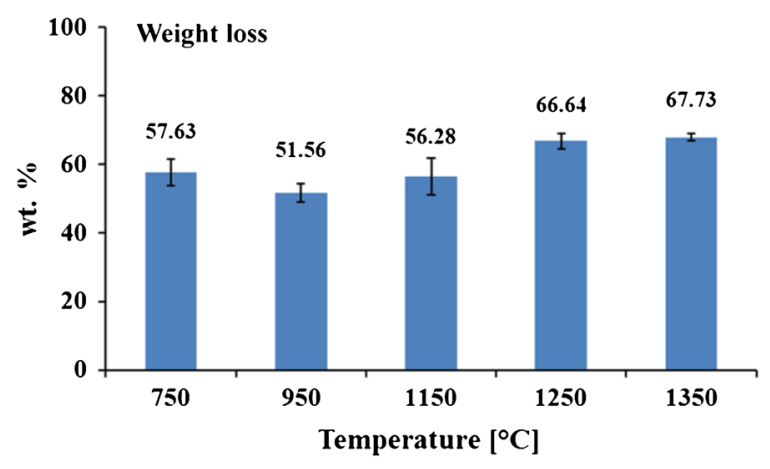

(a)

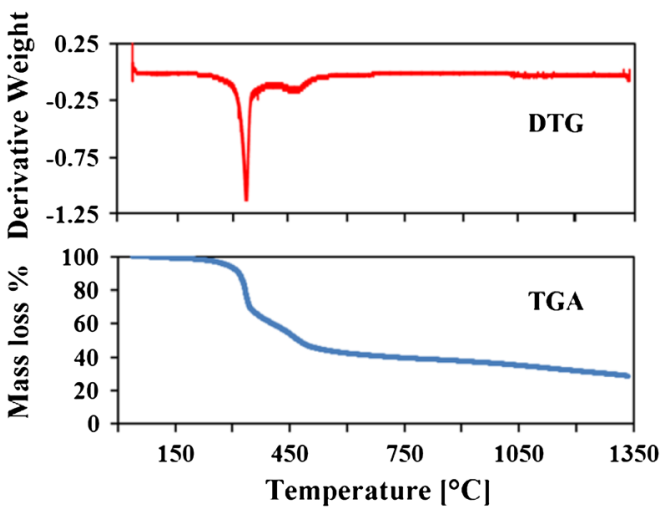

(b)

Fig. 2 a The weight loss as determined during heat treatment at a range of temperatures in the horizontal tube furnace, $\mathbf{b}$ the mass loss and the derivative weight as determined during TGA/DTG investigations at the heating rate of $20{ }^{\circ} \mathrm{C} / \mathrm{min}$

complex blend of polymers, metals and ceramics, are expected to be significantly different.

The carbon content of heat-treated PCB residues was determined using a LECO analyser; the results are plotted in Fig. 3. Although there is some scatter in data due to variations in waste PCB specimens under investigation, the carbon content was found to average around $60 \mathrm{wt} \%$ with values ranging between 52 and $74 \mathrm{wt} \%$. It is important to note that no attempt has been made to correlate the weight loss data as determined by the losses in the gaseous phase (Fig. 2) and the carbon content of the residue as determined by the nature/relative proportion of thermoplastic/thermosetting polymers present in waste PCBs (Fig. 3).

From the weight loss data and carbon content measurements, the amounts of carbon and metals/oxides recovered are summarised in Table 1 . The weight loss in column 2 indicates the loss in the gaseous phase caused by polymer degradation and other reactions, while the remaining solid residue is a mixture of carbon, metals and oxides. Although it was difficult to estimate the individual concentration of metals, oxides and carbons, an

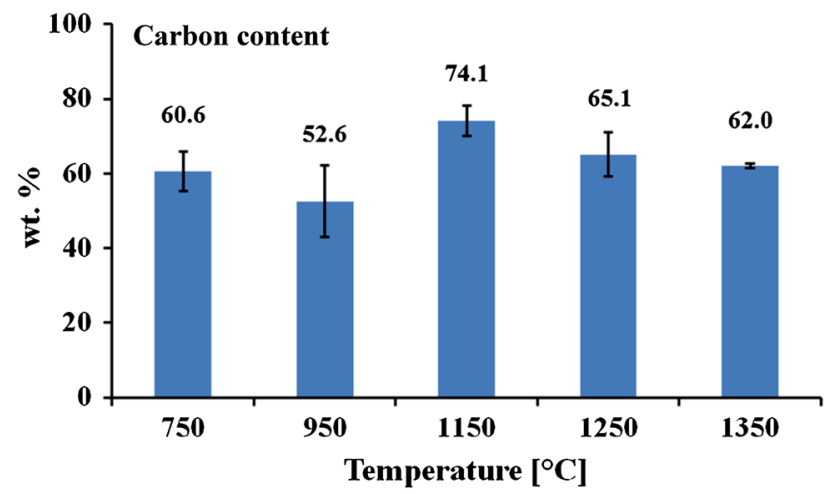

Fig. 3 The carbon content of residues obtained after heat treatment at a range of temperatures
Table 1 Average values of metals/oxides and carbons recovered during heat treatment at various temperatures ranging from 750 to $1,350{ }^{\circ} \mathrm{C}$

\begin{tabular}{llll}
\hline $\begin{array}{l}\text { Temperature } \\
\text { of heat } \\
\text { treatment }\left({ }^{\circ} \mathrm{C}\right)\end{array}$ & $\begin{array}{l}\text { Weight loss } \\
\text { through polymer } \\
\text { degradation }(\mathrm{wt} \%)\end{array}$ & $\begin{array}{l}\text { Metals/oxides } \\
\text { recovered } \\
(\mathrm{wt} \%)\end{array}$ & $\begin{array}{l}\text { Carbons } \\
\text { recovered } \\
(\mathrm{wt} \%)\end{array}$ \\
\hline 750 & 57.67 & 16.7 & 25.67 \\
950 & 51.56 & 24.9 & 24.48 \\
1,150 & 56.28 & 11.32 & 32.4 \\
1,250 & 66.34 & 11.64 & 21.7 \\
1,350 & 67.73 & 12.27 & 20.0 \\
\hline
\end{tabular}

approximate estimate of carbons and metals/oxides was obtained as follows. The carbon content in column 4 (Table 1) was computed using the relation: $(100-$ weight loss) $\times$ carbon fraction (from LECO measurements). The data in column 3 (metals/oxides) was computed as (100 weight loss $) \times(100-$ carbon fraction $)$. ICS analysis results on some of the major and minor metals are provided in a later section.

\section{Gas Generation}

Figure 4 shows a three-dimensional Fourier transform infrared spectrum (FTIR) obtained from the gases volatilised during the thermal decomposition (TGA) of polymerrich waste PCB in nitrogen atmosphere; FTIR is widely used to characterise volatile species evolving during pyrolysis. As the formation of volatile products was expected to occur mainly between 300 and $500{ }^{\circ} \mathrm{C}$, the FTIR spectrum was recorded in the temperature range 40-600 ${ }^{\circ} \mathrm{C}$. At low temperatures, a small amount of gaseous products such as $\mathrm{CO}_{2}$ and $\mathrm{HBr}$ were released. These compounds were identified by their characteristic bonds: 
Fig. 4 The 3D infrared spectrum of evolved gases during the pyrolysis of polymerrich waste PCBs between 40 and $600{ }^{\circ} \mathrm{C}$ (heating rate $20^{\circ} \mathrm{C} /$ min)

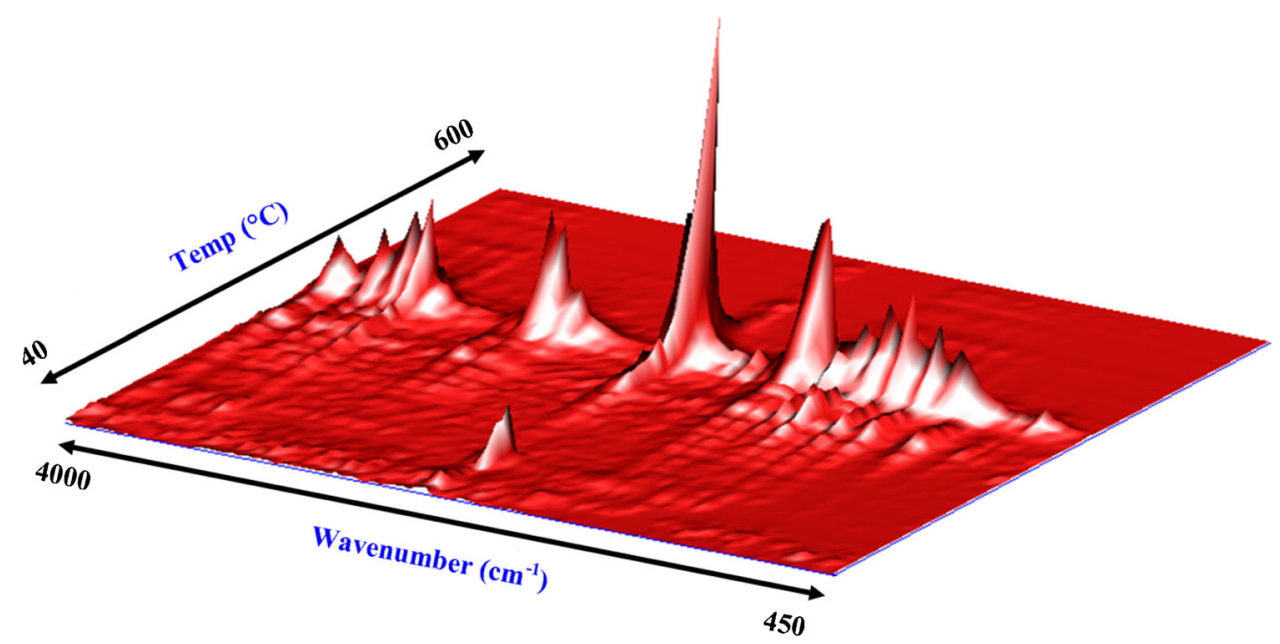

2,400-2,800 $\mathrm{cm}^{-1}$ for $\mathrm{HBr}$ and $2,200-2,400 \mathrm{~cm}^{-1}$ for $\mathrm{CO}_{2}$. The release of volatiles was found to increase after $300{ }^{\circ} \mathrm{C}$, and new absorption bands could clearly be seen. The formation of higher molecular organic volatiles was observed: characteristic absorption bands of bromo-phenol $\left(3,650 \mathrm{~cm}^{-1}\right)$, phenol $\left(3,600 \mathrm{~cm}^{-1}\right), \mathrm{H}_{2} \mathrm{O}\left(3,300 \mathrm{~cm}^{-1}\right)$, unsaturated $\mathrm{C}-\mathrm{H}$ in aromatics $\left(3,000 \mathrm{~cm}^{-1}\right), \quad \mathrm{CO}_{2}$ $\left(2,400 \mathrm{~cm}^{-1}\right), \mathrm{CO}\left(2,000 \mathrm{~cm}^{-1}\right)$, ketones and aldehydes $\left(1,750 \mathrm{~cm}^{-1}\right)$, benzene groups $\left(1,600\right.$ and $\left.1,500 \mathrm{~cm}^{-1}\right)$, ether groups $\left(1,250\right.$ and $\left.1,350 \mathrm{~cm}^{-1}\right), \mathrm{C}-\mathrm{O}$ vibration $\left(1,200 \mathrm{~cm}^{-1}\right)$ and substituted aromatic groups (between 600 and $900 \mathrm{~cm}^{-1}$ ) were observed. After $460{ }^{\circ} \mathrm{C}$, only small amounts of $\mathrm{CO}$ and $\mathrm{CO}_{2}$ were observed indicating possible carbonisation and char formation.

Gases $\left(\mathrm{CO}, \mathrm{CO}_{2}\right.$ and $\left.\mathrm{CH}_{4}\right)$ generated during the heat treatment $\left(750-1,350{ }^{\circ} \mathrm{C}\right)$ of waste PCBs in the horizontal tube furnace were also recorded continuously using an IR gas analyser. Cumulative volumes of gases released at two representative temperatures are shown in Fig. 5. At $1,150{ }^{\circ} \mathrm{C}$, there was a rapid release of gases as PCBs were introduced in the hot zone of the furnace; the level of $\mathrm{CO}$ released was found to be much higher than that of $\mathrm{CO}_{2}$ and $\mathrm{CH}_{4}$. While the emission of $\mathrm{CO}$ continued during the heating process, the generation of both $\mathrm{CO}_{2}$ and $\mathrm{CH}_{4}$ had become greatly reduced as indicated by the relatively flat cumulative volume plot. There were three key differences in gaseous emissions at $1,350^{\circ} \mathrm{C}$. Overall gas emissions were generally lower than the levels observed at $1,150{ }^{\circ} \mathrm{C}$; $\mathrm{CH}_{4}$ emissions had reduced by a factor of 2 . The sharp initial release of $\mathrm{CO}$ at $1,150{ }^{\circ} \mathrm{C}$ was replaced by a relatively gradual release of $\mathrm{CO}$ at $1,350{ }^{\circ} \mathrm{C}$. These results are significant as the polymer degradation and associated weight loss/volatile were expected to occur between 300 and $500{ }^{\circ} \mathrm{C}$; the gas generation at higher temperatures of $1,150{ }^{\circ} \mathrm{C}$ and beyond indicates additional reduction reactions/degradation of various PCB constituents. These
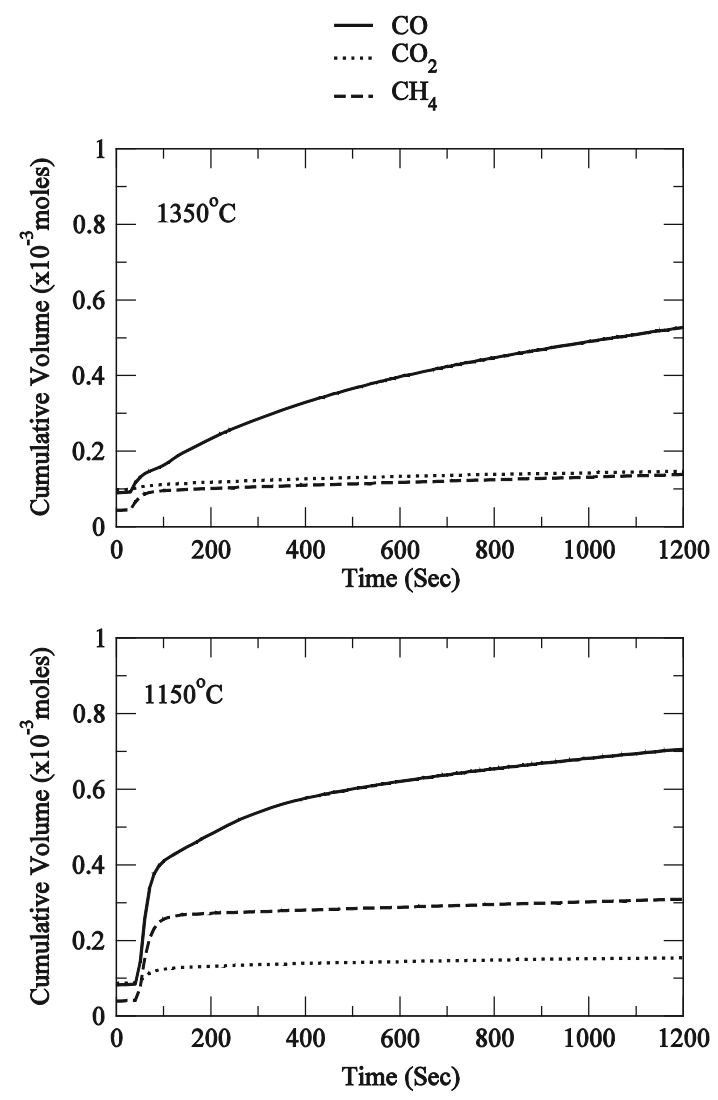

Fig. 5 Cumulative volumes of gases released during heat treatment in the horizontal tube furnace

results are consistent with TGA results (Fig. 2b) which showed a slow but continuous weight loss in this temperature regime.

\section{Structural Characterisation}

X-ray diffraction and Raman scattering studies were carried out on heat treated waste PCBs for structural 
characterisation of carbonaceous residues. While X-ray diffraction studies focus specifically on the long-range order developing in residual carbons, Raman scattering results help one quantify short range as well as molecularlevel order. While metals including copper, tin and lead were still mixed up with carbonaceous residues after heat treatment at temperatures below $950{ }^{\circ} \mathrm{C}$, these could be easily separated in the form of foils/droplets at higher temperatures. X-ray diffraction results on carbonaceous residues obtained after $20 \mathrm{~min}$ of heat treatment at 1,150 and $1,350{ }^{\circ} \mathrm{C}$ are shown in Fig. 6a. The diffraction pattern at $1,150{ }^{\circ} \mathrm{C}$ shows two broad peaks for carbon $\left(24.6^{\circ}\right.$ and $\left.44.1^{\circ}\right)$ and several sharp peaks belonging to various oxides such as silica, alumina, etc. and residual metals. The diffraction pattern at $1,350{ }^{\circ} \mathrm{C}$ also showed two broad peaks for carbon $\left(24.8^{\circ}\right.$ and $\left.44.1^{\circ}\right)$; however, the number and relative intensity of sharp peaks belonging to various oxides and residual metals had reduced significantly. It is likely that further chemical reactions could have partially consumed these materials. Graphitic carbon structure can be described by a regular, vertical stacking of hexagonal aromatic layers; the crystallite size of carbons can be represented by the vertical thickness of carbon net layer (Lc) [22]. Using Scherrer's formula, the Lc values of these carbons were determined to be $1.137\left(1,150^{\circ} \mathrm{C}\right)$ and $1.348 \mathrm{~nm}\left(1,350^{\circ} \mathrm{C}\right)$. This result indicates that graphitic crystals in the carbonaceous residues were only 3-4 layers thick, and the long-range order had not yet been established.

The structural features of residual carbons were also analysed by Raman spectroscopy, where the scattering process includes contributions from various phonon vibration modes of materials. The spectrum from e-waste residues after excitation with 514-nm laser light is shown in Fig. 6b. The spectrum has two peaks at around 1,585 and $1,350 \mathrm{~cm}^{-1}$. The peak at $1,350 \mathrm{~cm}^{-1}$, known as D (defect) band, is a feature representing disorder in graphitic structures $[23,24]$. The peak at $1,585 \mathrm{~cm}^{-1}$, known as $\mathrm{G}$ (graphite) band, represents highly ordered graphitic structure. The relative intensity ratio of $I_{\mathrm{D}} / I_{\mathrm{G}}$ bands was determined by computing areas under the peaks, which can be used to determine the extent of disorder/or the degree of graphitisation in the carbon structure. These were determined to be 2.018 at $1,150{ }^{\circ} \mathrm{C}$ and 1.83 at $1,350{ }^{\circ} \mathrm{C}$; this result indicates extensive disorder and poor graphitisation in the carbon structure. Both Raman and X-ray diffraction results are in good agreement and indicate these materials to be disordered carbons.

\section{Electron Microscopy Investigations}

Detailed SEM/EDS investigations were carried on e-waste residues after heat treatment in the temperatures ranging from 750 to $1,350{ }^{\circ} \mathrm{C}$. Two representative results are presented in this section. Figure 7a shows SEM/EDS results for waste PCBs heat treated at $750{ }^{\circ} \mathrm{C}$; various metals/ oxides had not yet separated at this temperature. The SEM indicates the presence of a number of metals $(\mathrm{Cu}, \mathrm{Sn}, \mathrm{Pb}$, etc.) as bright spots, carbon as dark regions and slag oxides $\left(\mathrm{Al}_{2} \mathrm{O}_{3}, \mathrm{Fe}_{2} \mathrm{O}_{3}, \mathrm{SiO}_{2}\right.$, etc. $)$ as light grey regions. While these were showing a tendency to segregate, they had not yet fully separated out. The metal separation started to become significant at temperatures higher than $950{ }^{\circ} \mathrm{C}$; significant amounts of carbonaceous residues were recovered at temperatures above $1,200{ }^{\circ} \mathrm{C}$. Figure $7 \mathrm{~b}$ shows SEM/EDS results from the carbonaceous material recovered after heat treatment at $1,350{ }^{\circ} \mathrm{C}$. This specimen was predominantly composed of carbon along with small clusters of silicon and aluminium oxides; metal concentrations in the carbonaceous residue had reduced significantly. While the LECO analysis determined the total carbon content in the residue, the EDS line scan in Fig. $7 \mathrm{~b}$ indicated that the carbon was distributed quite uniformly in the residue. A small amount of phosphorus was present as an impurity.

\section{Impurity Levels}

Detailed chemical composition of the carbonaceous residue was obtained through ICP-OES analysis; the results are summarised in Fig. 8. Even though metals had segregated out to a great extent at $1,150{ }^{\circ} \mathrm{C}$, the concentrations of major e-waste metals $(\mathrm{Cu}, \mathrm{Pb}$ and $\mathrm{Sn})$ in the carbonaceous residue were determined to be 5.74, 2.33 and $5.09 \mathrm{wt} \%$ respectively. Metal concentrations in the residue were found to decrease significantly with increasing temperatures. After heat treatment at $1,350{ }^{\circ} \mathrm{C}$ for $20 \mathrm{~min}$, the concentrations of $\mathrm{Cu}, \mathrm{Pb}$ and $\mathrm{Sn}$ had reduced to $0.46,0.03$ and $0.38 \mathrm{wt} \%$, respectively; especially the concentration of hazardous lead had become negligibly low. Corresponding concentrations of base metals from oxides such as $\mathrm{Fe}_{2} \mathrm{O}_{3}$, $\mathrm{Al}_{2} \mathrm{O}_{3}$ and $\mathrm{MgO}$ as part of the slag are also provided in the figure. These numbers were generally an order of magnitude smaller. Even though the presence of ceramics was quite high in the e-waste, these were found to be quite stable in the temperature range of $750-1,350{ }^{\circ} \mathrm{C}$. These did not interact either with polymers, metals or carbonaceous residue and tended to segregate out.

\section{Surface Area Measurement}

Surface area and pore distribution were studied through the nitrogen physisorption technique. A 20-point adsorption and 20-point desorption isotherms were generated, with data used to determine specific surface area using the BET model; the pore distribution was determined through the 
(a) X-ray Diffraction

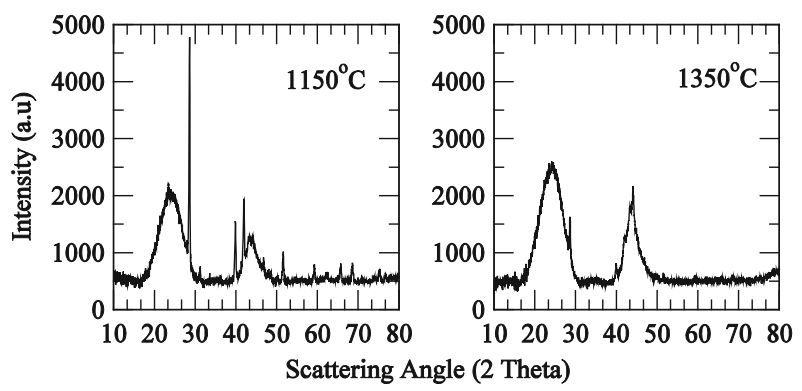

(b) Raman Scattering

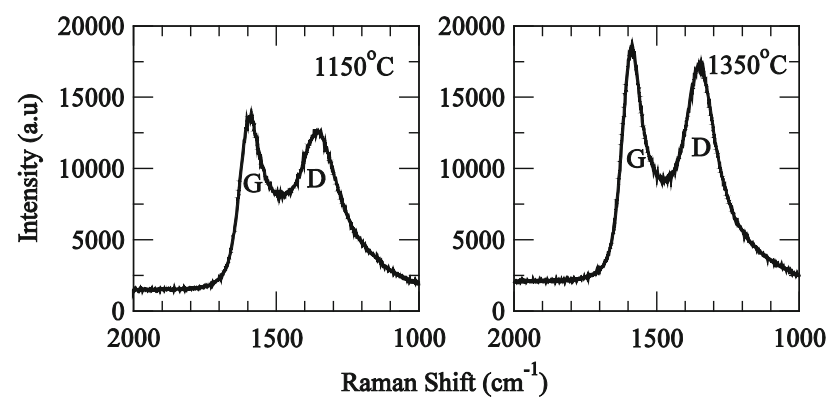

Fig. 6 a X-ray diffraction and b Raman scattering profiles from carbonaceous residues after heat treatment at 1,150 and $1,350{ }^{\circ} \mathrm{C}$

BJH model. Average results on pore width, surface area and volume of pores with sizes ranging between 1.7 and $300 \mathrm{~nm}$ from adsorption and desorption data are given in Table 2; corresponding results for the BET surface area have also been provided. Temperature did not have much influence on the average pore width which was found to range between 25.57 and $26.73 \mathrm{~nm}$. Average values for pore width, cumulative pore surface area, pore volume and BET surface areas were found to be the highest at $1,150{ }^{\circ} \mathrm{C}$. With the increasing temperature, the char showed signs of softening and fusing, resulting in a reduction in the number of pores and associated surface area. While the total BET surface area showed a continuous decrease with the increasing temperature, such welldefined trend was not observed for the average pore surface area and pore volume.

\section{Discussion}

The high-temperature pyrolysis of waste PCBs in the temperature range of $750-1,350{ }^{\circ} \mathrm{C}$ led to the segregation of metals, carbons and slag oxides; the amounts of carbon bearing materials produced were quite significant. Results in Table 1 indicate a significant carbon yield ranging between 20 and $32 \mathrm{wt} \%$; these numbers are much higher than typical quantities of chars produced by a range of polymers. The pyrolysis of $\mathrm{PVC}$ at $740{ }^{\circ} \mathrm{C}$ produced a maximum char of $9 \mathrm{wt} \%$; PS, PE and PP gave solid residues of $0.6,1.8$ and $1.6 \mathrm{wt} \%$, respectively, under these conditions. During pyrolysis at $850{ }^{\circ} \mathrm{C}$ under nitrogen atmosphere, PVC produced $5.9 \mathrm{wt} \%$ char; LDPE and HDPE produced only 0.2 and $2.3 \mathrm{wt} \%$ of chars, respectively [25, 26]. Our results indicate that polymer-rich e-waste, such as single-sided boards based on phenol formaldehyde resin, can produce high amounts of residual carbon. With carbon recovery reaching $32 \mathrm{wt} \%$ at $1,150{ }^{\circ} \mathrm{C}$; this is amongst the highest levels achieved in high-temperature transformation studies on polymeric waste.

The FTIR spectrum of gases evolved in the temperature range of $40-600{ }^{\circ} \mathrm{C}$ during TGA investigations showed the release of a range of organic volatiles, $\mathrm{CO} / \mathrm{CO}_{2}$ gases and several brominated compounds from bromine-based flame retardants in PCBs. One of the key issues associated with the heat treatment of waste PCBs is the generation of hazardous dioxins and furans. Guo et al. [27] have, however, established that the generation of toxic furans and dioxin becomes negligibly small at temperatures above $900{ }^{\circ} \mathrm{C}$; and the associated toxicity could be significantly reduced by adding $\mathrm{Ca}(\mathrm{OH})_{2}$ to leach out bromine from the flame retardants present in waste PCBs. Main gases generated at high temperatures were $\mathrm{CO}, \mathrm{CO}_{2}$ and $\mathrm{CH}_{4}$; their cumulative volume was seen to decrease at higher temperatures.

Detailed structural characterisation of carbons was carried out using X-ray diffraction and Raman scattering techniques. Observed carbons were found to have a predominantly disordered structure; the relative proportion of defect/graphitic structures was found to range from 2.018 $\left(1,150{ }^{\circ} \mathrm{C}\right)$ to $1.83\left(1,350{ }^{\circ} \mathrm{C}\right)$. The typical (002) peak for graphite occurs at $26.6^{\circ}$ representing the separation of basal planes stacked along the c-axis; covalently bonded $\left(\mathrm{sp}^{2}\right)$ carbon atoms in the basal planes are arranged on a hexagonal lattice. The (101) peak for graphite occurs at $44.67^{\circ}$. However, the carbonaceous residues from e-waste produced peaks that were located at slightly lower angles: $\left(24.6^{\circ}\right.$ and $\left.44.12^{\circ}\right)$ at $1,150{ }^{\circ} \mathrm{C}$ and $\left(24.8^{\circ}\right.$ and $\left.44.12^{\circ}\right)$ at $1,350{ }^{\circ} \mathrm{C}$. This shift indicates larger distances along the c-axis as well as in the basal plane for disordered carbons. Small values of $\mathrm{Lc}$ indicate the packing along the c-axis to be only 3-4 layers thick. However, high surface area was achieved for carbon residues at $1,150{ }^{\circ} \mathrm{C}$, which could lead to the possibility of producing activated carbons from waste PCBs. Future studies will investigate the high-temperature behaviour of $\mathrm{PCBs}$ at shorter times during the period of gaseous release and study the evolution of pore structure, number density and surface area prior to pore coalescence and condensation.

Electron microscopy results clearly indicated the phase separation of various e-waste constituents after heat treatment. Following polymer degradation at low temperatures and the formation of chars, both metals and ceramic oxides 
Fig. 7 The SEM/EDS results on carbonaceous residues after heat treatment at a $750{ }^{\circ} \mathrm{C}$ and b $1,350{ }^{\circ} \mathrm{C}$
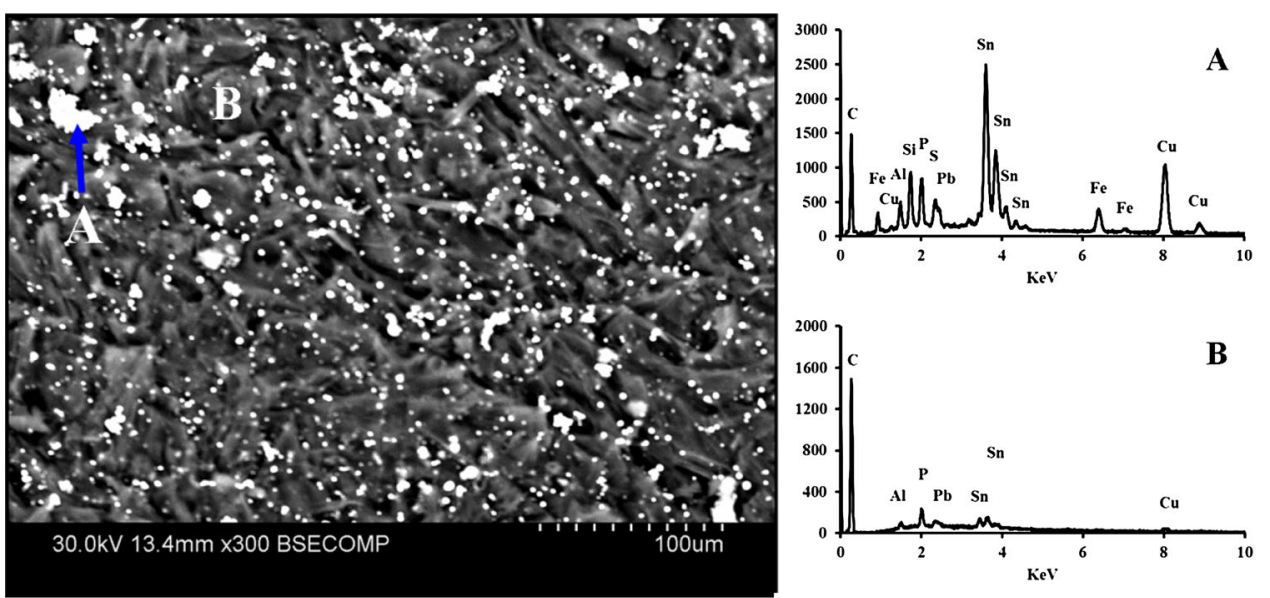

(a)
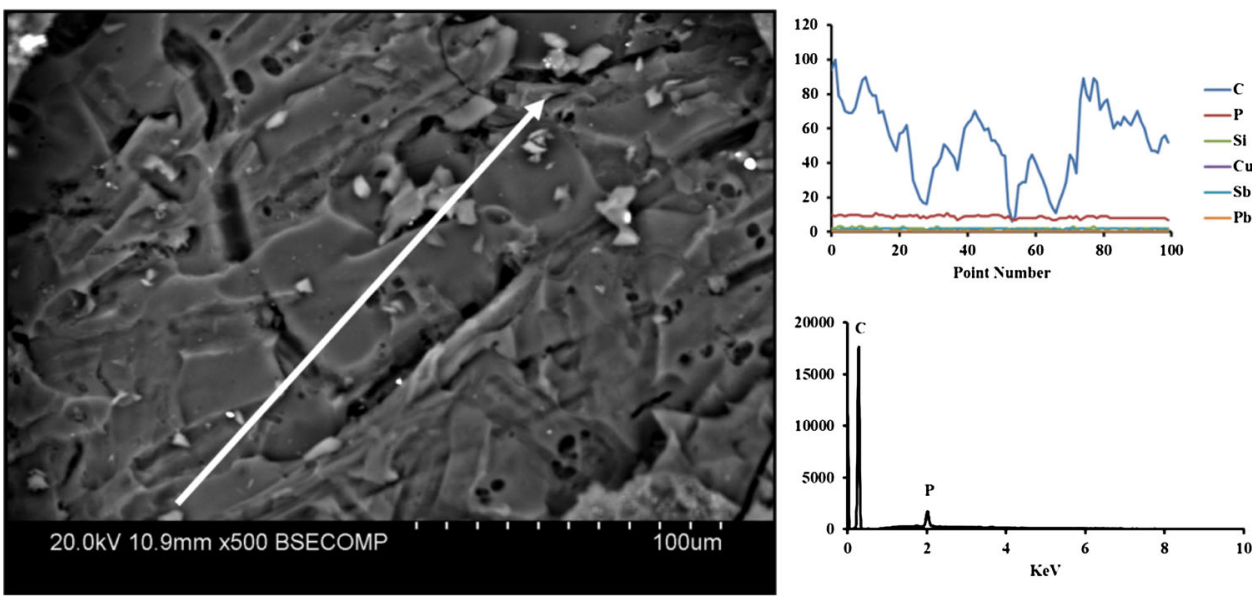

(b)
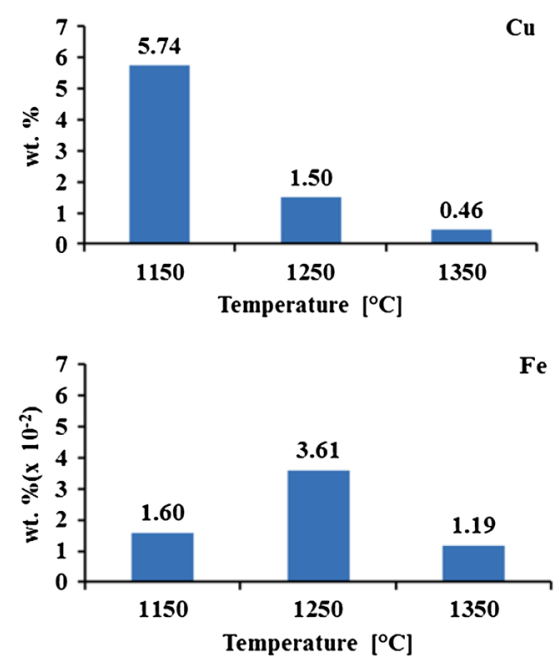
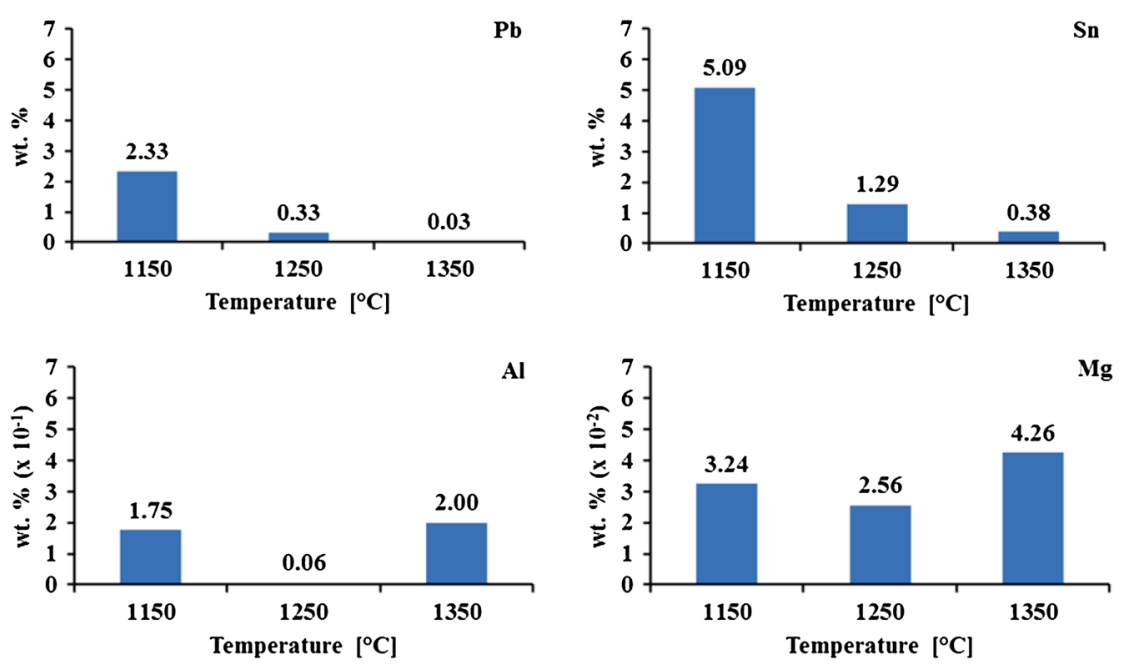

Fig. 8 Metallic concentrations in carbonaceous residues as determined by ICP analysis

started to segregate out at temperatures above $950{ }^{\circ} \mathrm{C}$. Line scans on residues after heat treatment at $1,350{ }^{\circ} \mathrm{C}$ showed extended regions composed mainly of carbon indicating a clear separation of the metallic phase and the precipitation of oxide phases. ICP analysis results showed that the concentration of major metals especially hazardous lead in 
Table 2 Average values of pore width, cumulative pore surface area and cumulative volume along with BET surface area

\begin{tabular}{lllll}
\hline $\begin{array}{l}\text { Temperature } \\
\text { of heat } \\
\text { treatment }\left({ }^{\circ} \mathrm{C}\right)\end{array}$ & $\begin{array}{l}\text { Pore } \\
\text { width } \\
(\mathrm{nm})\end{array}$ & $\begin{array}{l}\text { Cumulative } \\
\text { pore surface } \\
\text { area }\left(\mathrm{m}^{2} / \mathrm{g}\right)\end{array}$ & $\begin{array}{l}\text { Cumulative } \\
\text { pore volume } \\
\left(\mathrm{cm}^{3} / \mathrm{g}\right)\end{array}$ & $\begin{array}{l}\text { BET } \\
\text { surface } \\
\text { area } \\
\left(\mathrm{m}^{2} / \mathrm{g}\right)\end{array}$ \\
\hline 1,150 & 26.72870 & 0.38950 & 0.002605 & 7.3771 \\
1,250 & 26.62805 & 0.15925 & 0.001099 & 4.3800 \\
1,350 & 25.57250 & 0.21415 & 0.001378 & 3.4325 \\
\hline
\end{tabular}

the carbonaceous residue had dropped to very low levels at $1,350{ }^{\circ} \mathrm{C}$. Even the concentration of base metals from various oxides had become very low. The BET surface area of these carbonaceous resources showed a small dependence on temperature.

\section{Concluding Remarks}

Improper handling of e-waste results in vast amounts of toxic waste being sent into landfills which has the potential to leach into soil and ground water supplies. The carbon-bearing waste in landfills leads to the release of greenhouse gases, including huge amounts of $\mathrm{CO}_{2}$ and methane. Up to $50 \%$ of these emissions could be methane, which is 21 times more potent a greenhouse gas than $\mathrm{CO}_{2}$ [28]. With landfilling and incineration becoming less accepted and more expensive, recycling complex hazardous e-waste is no longer a choice but an essential future requirement. In this article, in-depth investigations were reported on the high-temperature transformations of polymer-rich waste PCBs. This study has shown that significant carbonaceous resources could be recovered from recycling electronic waste. These carbons could be used as a source of energy or be utilised in applications such as reduction reactions, carburisation, activated carbons, etc. These results have the potential to make a positive impact on the environment through waste management as the conventional resources have become increasingly scarce, and the need to conserve and recycle resources becomes even greater. This e-waste recycling approach is expected to lead to sustainable developments in the field resulting in increased environment protection and economic development.

Acknowledgments R. Cayumil gratefully acknowledges the financial support for this project from the Commonwealth Scientific and Industrial Research Organisation (CSIRO) and the Science and Industry Endowment Fund (SIEF). The authors would like to express their gratitude to the technical support of the Mark Wainwright Analytical Centre Units Electron Microscope and Solid State \& Elemental Analysis, of the University of New South Wales.

\section{References}

1. COM (2000) Proposal for a directive of the European Parliament and of the council on waste electrical and electronic equipment. Official Journal of the European Communities, Brussels, Belgium

2. Gover JE (1993) Review of the competitive status of the United States Electronics Industry. Technological competitiveness: contemporary and historical perspectives on the electrical, electronics, and computer industries. Institute of Electrical and Electronics Engineers IEEE, Piscataway, New York, pp 57-74

3. UNEP (2006) Call for global action on e-waste. United Nations Environment Programme

4. IAER (2006) International Association of electronics recyclers industry report. http://www.iaer.org/communications/indreporthtm

5. TEC (2008) Tipping point: Australia's e-waste crisis. Total Environment Centre, Australia

6. EPA US (2007) Management of electronic waste in the United States: approach 2. Washington DC

7. EPA US (2008) Electronics waste management in the United States: approach 1. Washington DC

8. Puckett J, Byster L, Westervelt S, Gutierrez R, Davis S, Hussain A, Dutta M (2002) Exporting harm: the high-tech trashing of Asia. The Basel Action Network, Seattle

9. Pinto V (2008) E-waste hazard: the impending challenge. Indian J Occup Environ Med 12:65-70. doi:10.4103/0019-5278.43263

10. Hall WJ, Williams PT (2007) Separation and recovery of materials from scrap printed circuit boards. Resour Conserv Recy 51:691-709. doi:10.1016/j.resconrec.2006.11.010

11. Cui J, Zhang L (2008) Metallurgical recovery of metals from electronic waste: a review. J Hazard Mater 158:228-256. doi:10. 1016/j.jhazmat.2008.02.001

12. Kasper A, Berselli G, Freitas B, Tenório J, Bernardes A, Veit H (2011) Printed wiring boards for mobile phones: characterization and recycling of copper. Waste Manag 31:2536-2545. doi:10. 1016/j.wasman.2011.08.013

13. Davis G, Herat S (2008) Electronic waste: the local government perspective in Queensland, Australia. Resour Conserv Recy 52:1031-1039. doi:10.1016/j.resconrec.2008.04.001

14. Schöner J, Hornung A, Sagi S, Seifert H (2004) Post-treatment of pyrolysis residues of WEEE. Recovery of precious metals. In: International conference on incineration and thermal treatment technologies, Phoenix, Arizona, May 10-14

15. Zhou Y, Wu W, Qiu K (2010) Recovery of materials from waste printed circuit boards by vacuum pyrolysis and vacuum centrifugal separation. Waste Manag 30:2299-2304. doi:10.1016/j.wasman. 2010.06.012

16. Flandinet L, Tedjar F, Ghetta V, Fouletier J (2012) Metals recovering from waste printed circuit boards (WPCBs) using molten salts. J Hazard Mater 213-214:485-490. doi:10.1016/j. jhazmat.2012.02.037

17. de Marco I, Caballero BM, Chomón MJ, Laresgoiti MF, Torres A, Fernández G, Arnaiz S (2008) Pyrolysis of electrical and electronic wastes. J Anal Appl Pyrolysis 82:179-183. doi:10. 1016/j.jaap.2008.03.011

18. Cayumil R, Khanna R, Ikram-Ul-Haq M, Rajarao R, Hill A, Sahajwalla V (2014) Generation of copper rich metallic phases from waste printed circuit boards. Waste Manag. doi:10.1016/j. wasman.2014.05.004

19. Rajarao R, Sahajwalla V, Cayumil R, Park M, Khanna R (2014) Novel approach for processing hazardous electronic waste. Proc Environ Sci 21:33-41

20. Condon JB (2006) Surface area and porosity determinations by physisorption: measurements and theory. Elsevier Science, Oxford 
21. Sahajwalla V, Zaharia M, Kongkarat MS, Khanna R, Rahman M, Saha-Chaudhury N, O'Kane P, Dicker J, Skidmore C, Knights D (2011) Recycling end of life polymers in electric arc furnace steelmaking process: fundamentals of polymer reactions with slag and metal. Energy Fuels 26:58-66

22. Li K, Khanna R, Zhang J, Liu Z, Sahajwalla V, Yang T, Kong D (2014) Factors affecting the evolution of coke structure in a blast furnace: a review. Fuel 133:194-215

23. Li X, Hayashi J-I, Li C-Z (2006) FT-Raman spectroscopic study of the evolution of char structure during the pyrolysis of a Victorian brown coal. Fuel 85:1700-1707

24. Sadezky A, Muckenhuber H, Grothe H, Niessner R, Pöschl U (2005) Raman microspectroscopy of soot and related carbonaceous materials: spectral analysis and structural information. Carbon 43:1731-1742
25. Demirbas A (2004) Pyrolysis of municipal plastic wastes for recovery of gasoline-range hydrocarbons. J Anal Appl Pyrolysis 72:97-102. doi:10.1016/j.jaap.2004.03.001

26. Zevenhoven R, Karlsson M, Hupa M, Frankenhaeuser M (1997) Combustion and gasification properties of plastics particles. J Air Waste Manage 47:861-870. doi:10.1080/10473289.1997. 10464461

27. Guo J, Guo J, Xu Z (2009) Recycling of non-metallic fractions from waste printed circuit boards: a review. J Hazard Mater 168:567-590. doi:10.1016/j.jhazmat.2009.02.104

28. Forster P et al (2007) Changes in atmospheric constituents and in radiative forcing. In: Solomon S et al (eds) Climate change 2007: The Physical Science Basis. Cambridge University Press, Cambridge 